\title{
EVALUATING ENVIRONMENTAL EFFICIENCY OF TURKISH CITIES BY DATA ENVELOPMENT ANALYSIS
}

ÜSTÜN A.K.*

Received: $13 / 06 / 2014$

Accepted: 22/04/2015

Available online: 24/04/2015
*Department of Industrial Engineering, Engineering Faculty Aksaray University, 68100, Aksaray, Turkey *to whom all correspondence should be addressed: e-mail: korkut.ustun@gmail.com

ABSTRACT

Turkey is a developing country and has achieved impressive economic development in recent years. But this rapid growth has brought in many environmental problems in Turkish cities, such as air pollution, water pollution etc. In order to eliminate these problems, environmental performances of the city administrations must be evaluated. The objective of this empirical study is to evaluate the environmental efficiency of 81 Turkish provinces for the year 2010 by using by Data Envelopment Analysis (DEA) technique. Efficient and inefficient units were determined in the system by four proposed DEA models. According to each model, the environmental efficiency maps of Turkey are constructed and the risky regions of the country are determined.

Keywords: Data Envelopment Analysis, mathematical modelling, environmental efficiency, air pollution, water pollution, Turkey, sustainable development

\section{Introduction}

Recent developments in technology and rapid economic growth have been accompanied by extensive environmental destruction in a global context. Human activity has damaged the natural integrity of major ecosystems on every continent, seriously threatening the security of the societies depending on these ecosystems (Roseland, 2000; Coli et al., 2011). In recent years Turkey has achieved rapid economic development leading to fast urbanization. However, growth at this speed has brought many environmental problems, such as air and water pollution from the dumping of chemicals, detergent and other waste products. These critical environmental problems have been important particularly in urban areas since the mid-1990s.

Data envelopment analysis (DEA) is a technique that measures the relative efficiencies of a Decision Making Unit (DMU). The technique was introduced by Charnes et al., (1978). Several studies have demonstrated how to use DEA based techniques to estimate environmental performance indices. Coli et al., (2011) measured the environmental efficiency of 103 Italian provinces for 2004 using a DEA technique. In their model they considered three kinds of variables; inputs, outputs and undesirable outputs. Kuosmanen and Kortelainen, (2005), constructed a general framework for a dynamic environmental performance analysis. Kortelainen, (2008), proposed an environmental performance index by applying frontier efficiency techniques and a Malmquist index approach applied to 20 member states of the European Union in 1990-2003. Kuosmanen and Kortelainen, (2007), used an environmental costbenefit analysis for the social evaluation of investment projects and policies that had significant environmental impacts. For this purpose, the authors proposed a DEA based method, which does not require price estimation for environmental impacts using stated or revealed preference methods. 
Kuosmanen et al., (2009), conducted an efficiency analysis of ten alternative timing strategies, taking into account the ancillary benefits. They implemented the approach proposed by Kuosmanen and Kortelainen, (2007), since it does not require a prior valuation of the environmental impacts. Munksgaard et al., (2007), demonstrated how to utilize the information on environmental damage costs within a DEA based environmental performance index and estimate these indices at the product level using Danish inputoutput data and environmental data from 1997. Managi and Kaneko, (2009), analyzed the performance of environmental management over time using province level data for 1992-2003. Burnett and Hansen, (2008), examined the relationship between environmental performance and productive efficiency in the United States electric utility industry before and after the 1990 Clean Air Act Amendments. Sarkis and Cordeiro, (2001), explored the relationship between environmental and financial performance at company level, using a comparison between the differential effects of pollution prevention efficiencies and end-of- pipe treatment approaches using DEA. Sarkis and Cordeiro, (2012), proposed a DEA model permitting the simultaneous consideration of 'good and bad' outputs in evaluating efficiency. They determined joint ecological and technical efficiencies of 437 of the largest fossil-fueled electricitygenerating plants in the United States. Using DEA Sueyoshi and Goto, (2010), explored the connection among environmental, operational and financial performance in the Japanese manufacturing industry.

Sustainable development can be defined as that which meets the needs of the present without compromising the ability of future generations to meet their own needs. Environmental efficiency is an important part of sustainable development. Yu and Wen, (2010), measured the urban environmental sustainability of 46 Chinese cities in 2007 using DEA and the Malmquist productivity index. Several indicators including economic, environmental, and resource sub-systems which are frequently involved in the concept of environmental sustainability are employed in the study. They indicate that the GDP per capita, city scale, and the industrial structure are influential factors in terms of environmental sustainability. Eco-efficiency is one of the primary tools used to promote a transformation from unsustainable development to that of sustainable growth. It is based on the concept of creating more goods and services while using fewer resources and creating less waste and pollution. In other words, ecoefficiency is the ratio between the value of what has been produced and the environment impacts of the product or service (Yu et al., 2013). Picazo-Tadeo et al., (2011), investigated China's eco-efficiency trends during the period 1978-2010. The eco-efficiency indicators showed an increase in resource utilization, energy consumption, emissions to air and water, and relative decoupling occurred in China at a higher level in the global context. Zhang et al., (2008), conducted an eco-efficiency analysis for regional industrial systems in China by developing DEA based models. In the study the pattern of the eco-efficiency of the regional industrial systems was presented using real data from 30 provinces in China.

In the related literature concerning DEA to our knowledge, there has been no application of the model to the environmental system of Turkey. This paper reports on a study in which four DEA models were employed to evaluate the environmental efficiency of 81 Turkish cities in 2010. For each model, environmental efficiency maps of Turkey are constructed.

The aims of this paper are:

- To apply the DEA concepts and principles, and develop a DEA modeling strategy that produces more accurate models to fit the structure of environmental efficiency in Turkish cities.

- To estimate efficiency scores using Turkish input-output data and environmental data from 2010.

- To construct clusters among Turkish cities with respect to the obtained efficiency scores.

The paper is organized as follows: Section 2 contains general information about DEA, explains the definitions of the DEA terms, and clarifies the classical DEA model formulations. Section 3 gives information about the study area and data. Section 4 presents the results of study and an analysis of the data. Finally, the concluding remarks are given in Section 5. 


\section{Data Envelopment Analysis}

DEA is a linear programming model for evaluating the performance of decision making units (DMUs). This method has been extensively used in performance evaluation and benchmarking of organizations such as military operations, education, health care, production and bank branches (Charnes et al., 1994).

If there are $\mathrm{n}$ DMUs each has $\mathrm{m}$ inputs and s outputs, the efficiency score of a DMU o is obtained by solving the following model proposed by Charnes et al., (1978).

$$
\operatorname{Max} \theta_{O}(v, u)=\frac{\sum_{r=1}^{s} u_{r} y_{r o}}{\sum_{i=1}^{m} v_{i} x_{i o}}
$$

s.t.

$$
\begin{aligned}
& \frac{\sum_{r=1}^{n} u_{r} y_{r j}}{\sum_{i=1}^{m} v_{i} x_{i j}} \leq 1,(j=1, \ldots, n) \\
& u_{1}, u_{2}, \ldots, u_{s} \geq 0 \\
& v_{1}, v_{2}, \ldots, v_{m} \geq 0
\end{aligned}
$$

The model can be converted to a decision model known as the CCR Model as given below (Cooper et al., 2000):

$$
\operatorname{Max} \theta_{o}(v, u)=\sum_{r=1}^{s} u_{r} y_{r o}
$$

s.t.

$$
\begin{aligned}
& \sum_{i=1}^{m} v_{i} x_{i o}=1 \\
& \sum_{r=1}^{s} u_{r} y_{r j} \sum_{i=1}^{m} v_{i} x_{i j} \geq 0, \quad(j=1,2 \ldots, n) \\
& u_{r}, v_{i} \geq 0
\end{aligned}
$$

where,

$\theta_{0}$ : Efficiency score of decision making unit "o",

$\mathrm{n}$ : number of DMUs,

s: number of outputs,

$\mathrm{m}$ : number of inputs,

$0: 1,2, \ldots \ldots . . n ; j=1,2, \ldots . . . n$,

$\mathrm{i}=1,2, . ., \mathrm{m} ; \mathrm{r}=1,2, \ldots, \mathrm{s}$,

$x_{i j}$ : amount of input i utilized by DMU $\mathrm{j}$,

$y_{r j}$ : amount of output $r$ produced by $\operatorname{DMU} j$,

$u_{r}$ : weight given to output $r$,

$v_{i}$ : weight given to input $\mathrm{i}$,

Another basic model is called as the BCC model which is proposed by Banker et al. (1984). This model is based on the dual model, and adds a restriction on $\lambda^{\prime}$ s. BCC

Model as follows: 
$\min \theta 0$

s.t

$$
\begin{aligned}
& \sum_{j} \lambda_{j} x_{i j}-\theta_{o} x_{i o} \leq 0 \\
& \sum_{j} \lambda_{j} y_{r j}-y_{r o} \geq 0 \\
& \sum_{j} \lambda_{j}=1 \\
& \lambda_{j} \geq 0
\end{aligned}
$$

Where $y_{r j}$ is the amount of $r^{\text {th }}$ output for $j^{\text {th }}$ DMU and $x_{i j}$ is the amount of input for the same DMU. $\lambda$ is the non-negative vector. The BCC model evaluates the efficiency of $O_{\text {th }} \operatorname{DMU}(O=1, \ldots, n)$ by solving the above $\mathrm{LP}$ problem. A DMU is BCC efficient if it has a relative efficiency score of 1 , and a relative efficiency score less than 1 shows the inefficiency of the DMU (Mondal and Chakraborty, 2013).

The models given above are run $\mathrm{n}$ times and the relative efficiency scores of all the DMUs are calculated. In the model, each DMU takes input and output weights that maximize its efficiency score. If any DMUs efficiency score is 1 , then this DMU is considered efficient, otherwise it is inefficient (Cooper et al., 2000).

DEA method is used in many areas because it has some advantages. First of all, DEA can compare each DMU by a single efficiency score. Secondly, DEA can show some areas of improvements for each single DMU by projecting inefficient units on the efficient frontier.Thirdly, DEA can assist making inferences on the DMUs' general profile. Moreover, DEA can use multiple inputs and outputs stated in different measurement units. Furthermore DEA focus on a best-practice frontier, instead of population centraltendencies. Every unit is compared to an efficient unit or a combination of efficient units. Finally, no restrictions are imposed on the functional form relating inputs to outputs.

However, DEA models have some limitations. Firstly DEA is an extreme point technique, and selecting wrong inputs/outputs errors can cause significant problems. Secondly, large problems can be computationally intensive, because DEA generates a separate linear program for each DMU. There are some packages which facilitate the processing of large amounts of data. Thirdly, DEA has limitations in aggregating different aspects of efficiency, especially in the case where DMUs perform multiple activities. Moreover, the difficulty of mixing different dimensions of the analysis is another problem of DEA. For example, assume a DMU performing two different functions. The DMU may be efficient in the first function and inefficient in the second function. This problem can be solved by two separate DEA models, because relevant inputs and outputs for each dimension are not directly comparable. Furthermore, DEA does not specifically address absolute efficiency. It informs only how well the DMU is doing compared to the efficient units, but not compared to a theoretical maximum (Ramanathan, 2003; Üstün and Barbarosoğlu, 2015).

\section{Data}

As mentioned above, DEA was applied to 81 Turkish cities to evaluate their efficiency in 2010. In order to model the relative efficiency of a set of DMUs, every city administration of Turkey is considered to be a DMU.

For the implementation of DEA, the most important stage is the selection of inputs and outputs because inputs and outputs lead to incorrect results and diagnoses for the efficiency of organizations (Cooper et al., 2000). Table 1 presents outputs and inputs used in the study. 
Table 1. Inputs and Outputs

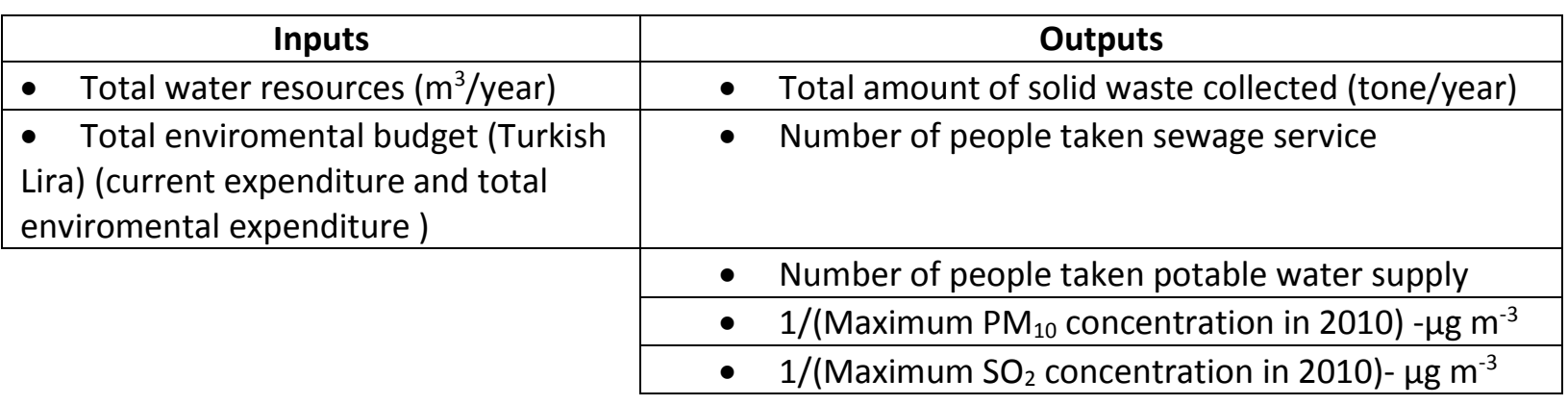

Air pollution is a very serious problem for many countries and the negative effects on human health have been verified by various researchers. The $\mathrm{PM}_{10}$ and $\mathrm{SO}_{2}$ concentrations $\left(\mu \mathrm{g} / \mathrm{m}^{3}\right)$ are two of the most important parameters which provide information about a city's air pollution. Sulfur dioxide $\left(\mathrm{SO}_{2}\right)$ mostly originating from the oxidation of sulfur compounds is one of the most dangerous polluters of the environment and air (Periera et al., 2007, Nikolić et al., 2010). Suspended particles of $\mathrm{PM}_{10}$ are another example of serious ambient air polluters which harm public health (Koelemeijer et al., 2006). PM 10 particles often cause respiratory and cardiovascular diseases and increase mortality (Kappos et al., 2004, Nikolić et al., 2010). These two variables $\gamma$ and $\beta$ are considered to be the undesirable outputs, termed and are calculated as follows:

\section{$\gamma=1 /\left(/\right.$ (Maximum $\mathrm{SO}_{2}$ concentration in 2010 in that city)}

$\beta=1 / /\left(\right.$ (Maximum $\mathrm{PM}_{10}$ concentration in 2010 in that city)

The amount of municipal solid waste collected by the municipalities (ton/year), the number of people served by the sewerage system, and number of people served by the water supply networks and water treatment plants in municipalities are the other three outputs in the study.

The first input is the total of the water resources of the city ( $\mathrm{m}^{3} /$ year). The current and investment expenditure on environmental services (Turkish Lira) are the two financial inputs. The current expenditure consists of salaries, government premium to social security agencies, purchase of goods, materials and environmental services; the investment expenditure includes purchase of machinery, equipment and motor vehicles and expenses for buildings, facilities, repair and maintenance.

All the data was obtained from the Turkish Statistical Institute with the air quality, waste, and financial statistics being provided by the related provincial centers in Turkey (www.turkstat.gov).

\section{Results and Discussion}

In this section the results obtained by applying the four DEA models are presented. The scores were computed using Model A, B, C, and D. As stated in Section 2, DEA is a flexible technique that produces efficiency scores that differ when alternative sets of inputs and outputs are used. All DEA models in the study have same output variables. However, in Model A and Model B, current expenditure, total environmental expenditure, and total water resources are the input variables; however, in Model $C$ and Model $D$, the total environmental budget (consisting of current expenditure and total environmental expenditure) and total water resources are used as input variables. Model $A$ and Model $C$ are CCR based models (Charnes et al., 1978), on the other hand Model B and Model D are based on BCC Models (Banker at al., 1984).

The primal linear programs associated with the models are solved using Efficiency Measurement Systems (EMS) software package developed by Holger Scheel, (2000). The environmental efficiency scores obtained from the four models are listed in Table 2.

According to the results, the DMUs that were on the efficiency frontier in all the models are; Istanbul, Konya, Balıkesir, Kırıkkale, Manisa, Ardahan, Bingöl, Niğde, Sinop, Tokat, Trabzon, Tunceli, and Yalova. Moreover, DMUs of Elazı̆̆, Hatay, Van, Ankara, Bursa, Osmaniye, Artvin, Adana, Kahramanmaraş Malatya, 
Kırklareli, Bilecik, Giresun, Izmir are efficient according to the BCC (Model B and D) scores; however, their efficiency scores are lower than $100 \%$ in CCR. Furthermore, the BCC models efficiency score of any DMU is equal to or higher than the CCR (Model A and Model C) efficiency score for the same DMU.

Table 2. Efficiency Scores of DMUs

\begin{tabular}{|c|c|c|c|c|c|c|c|c|c|}
\hline DMU & Model A & Model B & Model C & Model D & DMU & Model A & Model B & Model C & Model D \\
\hline Adana & $37,81 \%$ & $100,00 \%$ & $32,71 \%$ & $100,00 \%$ & K.maras & $50,75 \%$ & $100,00 \%$ & $46,70 \%$ & $100,00 \%$ \\
\hline Adıyaman & $35,90 \%$ & $56,29 \%$ & $33,94 \%$ & $52,59 \%$ & Karabük & $34,64 \%$ & $34,80 \%$ & $30,75 \%$ & $31,01 \%$ \\
\hline Afyon & $52,92 \%$ & $87,15 \%$ & $42,19 \%$ & $71,48 \%$ & Karaman & $41,86 \%$ & $47,95 \%$ & $41,47 \%$ & $47,37 \%$ \\
\hline Ağrı & $62,83 \%$ & $75,17 \%$ & $62,40 \%$ & $72,69 \%$ & Kars & $31,02 \%$ & $83,40 \%$ & $27,83 \%$ & $33,81 \%$ \\
\hline Aksaray & $27,16 \%$ & $27,22 \%$ & $25,57 \%$ & $26,24 \%$ & Kastamonu & $35,34 \%$ & $43,58 \%$ & $34,31 \%$ & $39,09 \%$ \\
\hline Amasya & $32,33 \%$ & $35,03 \%$ & $20,20 \%$ & $34,85 \%$ & Kayseri & $74,38 \%$ & $100,00 \%$ & $73,10 \%$ & $100,00 \%$ \\
\hline Ankara & $48,03 \%$ & $100,00 \%$ & $39,54 \%$ & $99,32 \%$ & Kırıkkale & $100,00 \%$ & $100,00 \%$ & $100,00 \%$ & $100,00 \%$ \\
\hline Antalya & $100,00 \%$ & $100,00 \%$ & $94,49 \%$ & $94,61 \%$ & Kırklareli & $88,53 \%$ & $100,00 \%$ & $85,60 \%$ & $100,00 \%$ \\
\hline Ardahan & $100,00 \%$ & $100,00 \%$ & $100,00 \%$ & $100,00 \%$ & Kırşehir & $100,00 \%$ & $100,00 \%$ & $59,03 \%$ & $83,73 \%$ \\
\hline Artvin & $87,98 \%$ & $100,00 \%$ & $81,88 \%$ & $100,00 \%$ & Kilis & $19,80 \%$ & $24,00 \%$ & $16,69 \%$ & $22,83 \%$ \\
\hline Aydın & $63,17 \%$ & $81,90 \%$ & $63,08 \%$ & $67,73 \%$ & Kocaeli & $37,92 \%$ & $55,40 \%$ & $37,74 \%$ & $46,62 \%$ \\
\hline Balıkesir & $100,00 \%$ & $100,00 \%$ & $100,00 \%$ & $100,00 \%$ & Konya & $100,00 \%$ & $100,00 \%$ & $100,00 \%$ & $100,00 \%$ \\
\hline Bartın & $49,62 \%$ & $58,78 \%$ & $48,06 \%$ & $57,60 \%$ & Kütahya & $39,13 \%$ & $79,70 \%$ & $35,51 \%$ & $75,99 \%$ \\
\hline Batman & $58,28 \%$ & $61,31 \%$ & $50,81 \%$ & $51,05 \%$ & Malatya & $45,56 \%$ & $100,00 \%$ & $43,99 \%$ & $91,95 \%$ \\
\hline Bayburt & $34,04 \%$ & $40,95 \%$ & $30,63 \%$ & $39,57 \%$ & Manisa & $100,00 \%$ & $100,00 \%$ & $100,00 \%$ & $100,00 \%$ \\
\hline Bilecik & $67,05 \%$ & $100,00 \%$ & $58,92 \%$ & $100,00 \%$ & Mardin & $72,99 \%$ & $73,37 \%$ & $72,89 \%$ & $73,29 \%$ \\
\hline Bingöl & $100,00 \%$ & $100,00 \%$ & $100,00 \%$ & $100,00 \%$ & Mersin & $48,20 \%$ & $100,00 \%$ & $48,04 \%$ & $100,00 \%$ \\
\hline Bitlis & $31,00 \%$ & $42,44 \%$ & $30,88 \%$ & $42,41 \%$ & Muğla & $40,20 \%$ & $74,87 \%$ & $39,47 \%$ & $70,51 \%$ \\
\hline Bolu & $69,28 \%$ & $69,32 \%$ & $59,64 \%$ & $60,51 \%$ & Muş & $22,73 \%$ & $25,11 \%$ & $21,47 \%$ & $95 \%$ \\
\hline Burdur & $63,59 \%$ & $63,66 \%$ & $48,75 \%$ & $49,35 \%$ & Nevşehir & $59,55 \%$ & $59,85 \%$ & $55,94 \%$ & $57,39 \%$ \\
\hline Bursa & $46,64 \%$ & $100,00 \%$ & $40,73 \%$ & $100,00 \%$ & Niğde & $100,00 \%$ & $100,00 \%$ & $100,00 \%$ & $100,00 \%$ \\
\hline Çanakkale & $39,60 \%$ & $56,99 \%$ & $38,08 \%$ & $52,03 \%$ & Ordu & $26,57 \%$ & $50,26 \%$ & $25,32 \%$ & $43,00 \%$ \\
\hline Çankırı & $35,03 \%$ & $43,28 \%$ & $33,32 \%$ & $43,14 \%$ & Osmaniye & $79,74 \%$ & $100,00 \%$ & $75,92 \%$ & $100,00 \%$ \\
\hline Çorum & $40,25 \%$ & $45,74 \%$ & $38,37 \%$ & $42,55 \%$ & Rize & $33,61 \%$ & $46,14 \%$ & $32,04 \%$ & $42,78 \%$ \\
\hline Denizli & $42,94 \%$ & $79,48 \%$ & $25,66 \%$ & $51,82 \%$ & Sakarya & $30,59 \%$ & $49,69 \%$ & $29,76 \%$ & $47,96 \%$ \\
\hline Diyarbakır & $48,48 \%$ & $67,72 \%$ & $47,20 \%$ & $57,41 \%$ & Samsun & $34,72 \%$ & $97,48 \%$ & $31,91 \%$ & $96,94 \%$ \\
\hline Düzce & $47,73 \%$ & $98,95 \%$ & $37,69 \%$ & $55,72 \%$ & Siirt & $45,87 \%$ & $46,35 \%$ & $42,97 \%$ & $43,19 \%$ \\
\hline Edirne & $40,89 \%$ & $59,25 \%$ & $40,52 \%$ & $58,15 \%$ & Sinop & $100,00 \%$ & $100,00 \%$ & $100,00 \%$ & $100,00 \%$ \\
\hline Elazı̆̆ & $88,41 \%$ & $100,00 \%$ & $68,24 \%$ & $73,74 \%$ & Sivas & $83,78 \%$ & $94,54 \%$ & $79,19 \%$ & $79,76 \%$ \\
\hline Erzincan & $50,60 \%$ & $53,17 \%$ & $49,65 \%$ & $53,06 \%$ & & $65,22 \%$ & $75,52 \%$ & $64,93 \%$ & $72,90 \%$ \\
\hline Erzurum & $22,20 \%$ & $44,31 \%$ & $20,11 \%$ & $41,33 \%$ & Şırnak & $49,25 \%$ & $70,60 \%$ & $48,84 \%$ & $65,54 \%$ \\
\hline Eskişehir & $39,78 \%$ & $67,50 \%$ & $37,14 \%$ & $67,03 \%$ & Tekirdağ & $76,39 \%$ & $77,32 \%$ & $75,93 \%$ & $76,97 \%$ \\
\hline Gaziantep & $44,45 \%$ & $99,91 \%$ & $36,10 \%$ & $96,80 \%$ & Tokat & $100,00 \%$ & $100,00 \%$ & $100,00 \%$ & $100,00 \%$ \\
\hline Giresun & $24,67 \%$ & $100,00 \%$ & $17,62 \%$ & $100,00 \%$ & Trabzon & $100,00 \%$ & $100,00 \%$ & $100,00 \%$ & $100,00 \%$ \\
\hline Gümüşhane & $42,96 \%$ & $77,27 \%$ & $42,82 \%$ & $72,61 \%$ & Tunceli & $100,00 \%$ & $100,00 \%$ & $100,00 \%$ & $100,00 \%$ \\
\hline Hakkari & $42,61 \%$ & $49,92 \%$ & $40,22 \%$ & $49,33 \%$ & Uşak & $53,45 \%$ & $64,63 \%$ & $38,88 \%$ & $45,56 \%$ \\
\hline Hatay & $85,92 \%$ & $100,00 \%$ & $85,83 \%$ & $100,00 \%$ & Van & $96,33 \%$ & $100,00 \%$ & $65,54 \%$ & $66,29 \%$ \\
\hline Iğdır & $95,68 \%$ & $96,84 \%$ & $37,30 \%$ & $37,75 \%$ & Yalova & $100,00 \%$ & $100,00 \%$ & $100,00 \%$ & $100,00 \%$ \\
\hline Isparta & $59,42 \%$ & $93,57 \%$ & $56,63 \%$ & $83,39 \%$ & Yozgat & $68,30 \%$ & $100,00 \%$ & $66,88 \%$ & $100,00 \%$ \\
\hline İstanbul & $100,00 \%$ & $100,00 \%$ & $100,00 \%$ & $100,00 \%$ & Zonguldak & $44,43 \%$ & $77,64 \%$ & $43,06 \%$ & $48,52 \%$ \\
\hline İzmir & $40,55 \%$ & $100,00 \%$ & $40,50 \%$ & $95,34 \%$ & & & & & \\
\hline
\end{tabular}




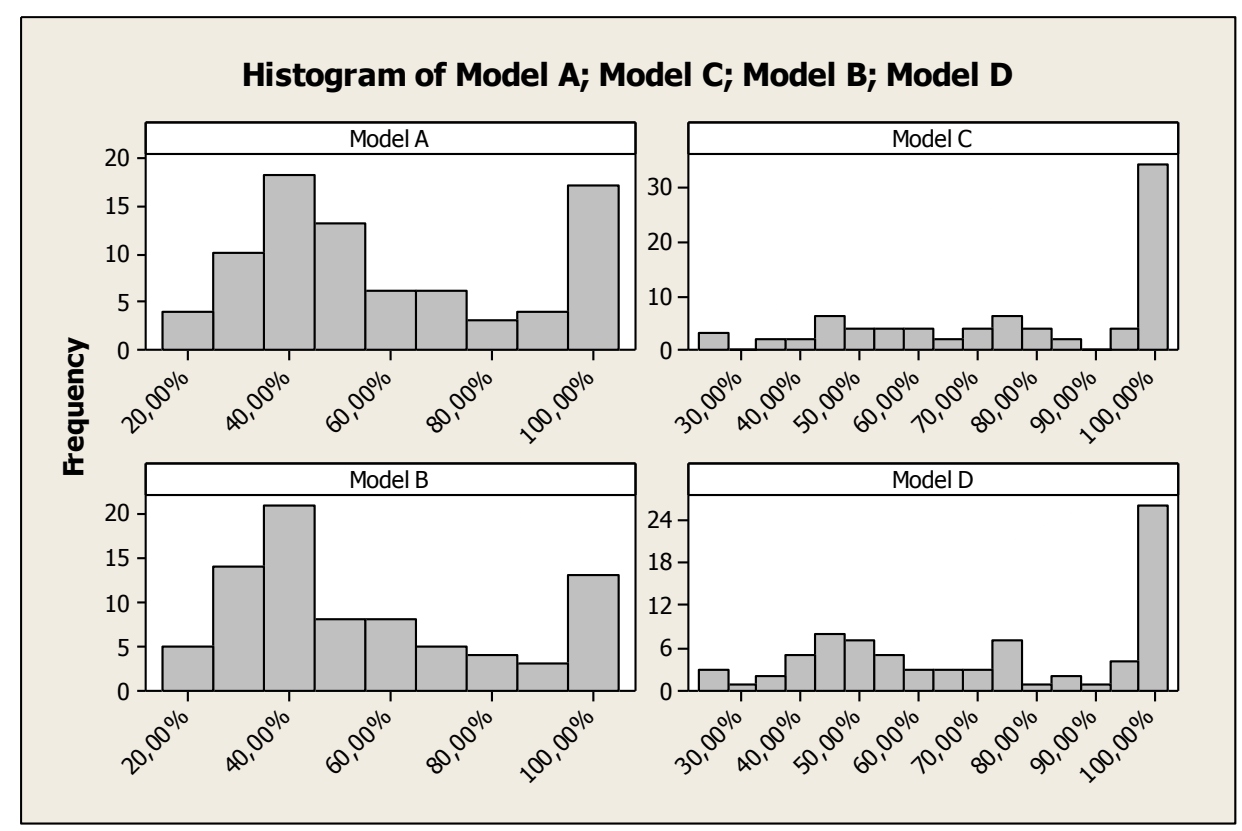

Figure 1. Histogram of Results

Figure 1 presents the distribution of efficiency scores of the DMUs obtained by the models. Histograms were obtained using Minitab software (www.minitab.com). The area in Figure 1 for the result for Model $B$ and Model $D$ are more spread out than those of Model $A$ and Model $C$ results indicating a more variable distribution of the efficiency scores.

Table 3. Summary of Results

\begin{tabular}{lllll}
\multicolumn{1}{c}{ Statistics } & Model A & Model B & Model C & Model D \\
\hline Mean & $59,64 \%$ & $77,60 \%$ & $54,93 \%$ & $71,35 \%$ \\
\hline Min & $19,80 \%$ & $24,00 \%$ & $16,69 \%$ & $22,83 \%$ \\
\hline Max & $100,00 \%$ & $100,00 \%$ & $100,00 \%$ & $100,00 \%$ \\
\hline Std. dev. & 0,04681 & 0,158109 & 0,073186 & 0,364019 \\
\hline \# of efficient unit & 15 & 32 & 13 & 25 \\
\hline \# of inefficient unit & 66 & 49 & 68 & 56
\end{tabular}

Table 3 presents a summary of the environmental efficiency ratings for all the provinces. The mean environmental efficiency score of Turkish cities in the study is $59.64 \%$ for Model A, $77.6 \%$ for Model B, $54.93 \%$ for Model C, and $71.35 \%$ for Model D. Specifically, scores lower than this mean imply that there is a need for these DMUs to further improve efficiency in order to achieve the best practice. Central government also needs to support the city administrations by creating an appropriate policy environment that promotes efficiency. Table 3 also shows that, according to Model A, 15 DMUs are efficient, Model C shows that 13 DMUs are efficient while according to Model B and Model D, 32 and 25 DMUs respectively are efficient frontier. Kilis has the minimum efficiency score since it achieved scores of $19.80 \%, 24 . \%$, $16.69 \%$, and $22.83 \%$ in all four models.

The environmental efficiency maps of Turkey were constructed from the model results. As shown in Figure 2, the cities in the Middle Anatolian Region, Mediterranean Region, Aegean Region, Marmara Region and some parts of East Anatolian Region appear to be more efficient users of the input quantities to produce a given output as compared to the other city administrations. This means that there are inefficiencies in the use of these inputs among the inefficient city administrations, which these DMUs need to remedy to achieve increased efficiency. 

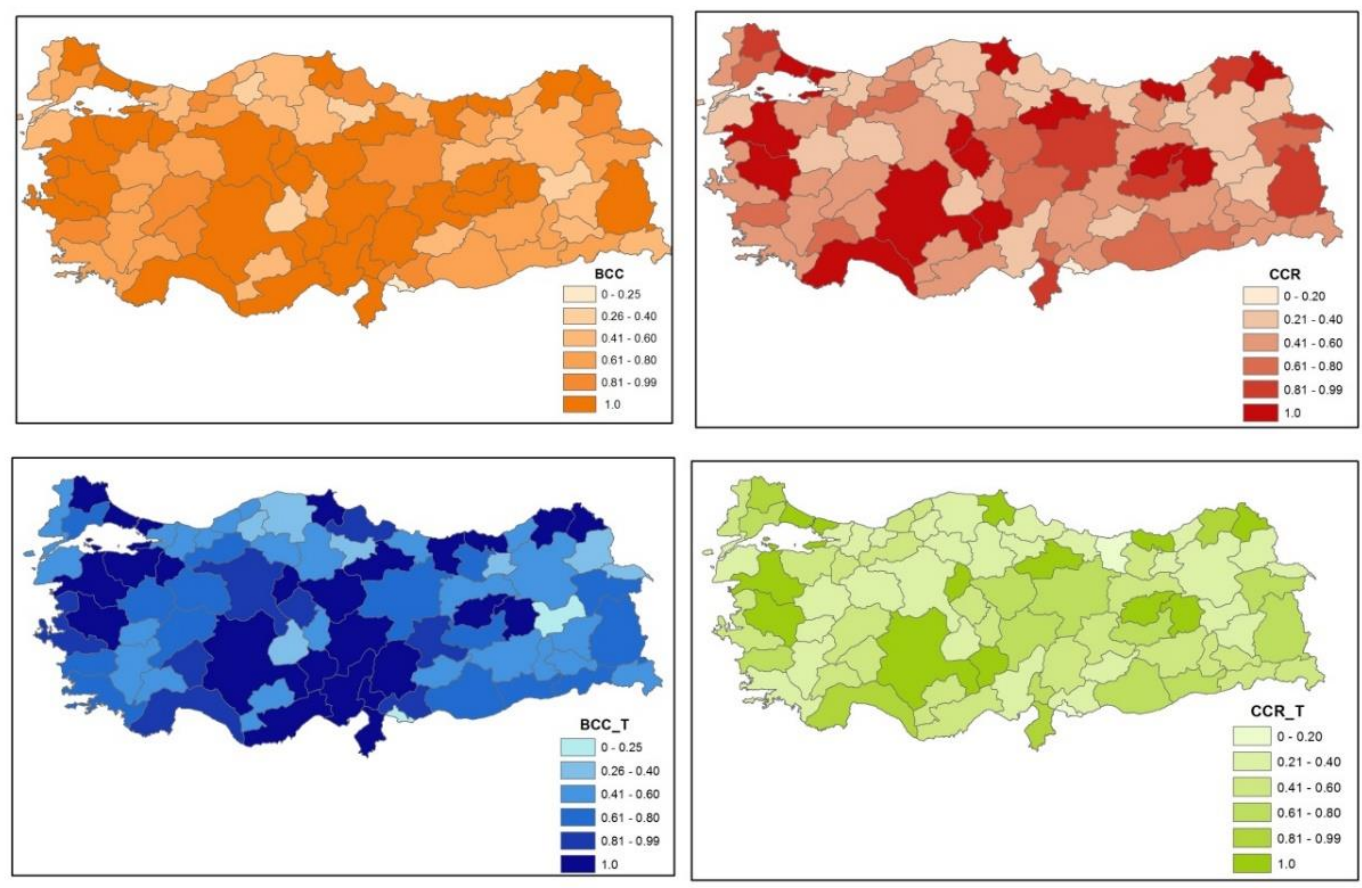

Figure 2. Enviromental Efficiency maps of Turkey

\section{Conclusion}

This study presented the environmental efficiency of Turkish cities using a non-parametric approach to efficiency measurement, represented by DEA technique. Sustainable development consists of economic and environmental dimensions (Coli et al., 2011). Hence, environmental efficiency is of great importance for decision makers. In this study two dimensions of sustainable development are taken into consideration to determine the environmental efficiencies of Turkish cities. Using data published by the Turkish Statistical Institute, the relative efficiency score of Turkish cities were calculated for the year 2010 using four DEA models.

Several studies about environmental efficiency evaluation were found in the literature; however, there was no DEA application in environmental efficiency for Turkish cities. Thus, the current study is the first DEA implementation in Turkish cities.

One of the contributions of this study to the enhancement of environmental management in Turkey is that it provides a way for inefficient DMUs to determine the causes of their inefficiencies thus these DMUs can take measures to remove or reduce their inefficiencies, and be better prepared for future environmental disasters. This study also shows the potential use of DEA to determine and evaluate the effectiveness of the environmental activities of Turkish city administrations. The results of the study can help local and central authorities to improve environmental policies and regulations. Moreover, the efficient and inefficient units in Turkish cities are determined, according to environmental efficiency. Furthermore, target inputs and outputs are determined by peer DMUs for inefficient units. In addition, different DEA models are implemented and the resulting similarities and differences are investigated. Also, environmental efficiency maps are constructed and they can show where the environmental risk areas of regions are located.

The models implemented in this research can be improved. First, additional key variables in the form of other environmental pressures can be added to evaluate the performance of the DMUs. Secondly, the 
model can be extended to further application studies to compare the ecological performance with other countries. In the current study, CCR and BCC Models were employed; in future work other DEA models can be applied.

\section{References}

Banker R.D., Charnes A. and Cooper W.W. (1984), Some Models for Estimating Technical and Scale Inefficiencies in Data Envelopment Analysis, Management Science, 30, pp. 1078-1092.

Burnett R.D. and Hansen D.R. (2008), Ecoefficiency: Defining a role for environmental cost management, Accounting, Organizations and Society, 33(6), 551-581.

Charnes A., Cooper W.W. and Rhodes E. (1978), Measuring the efficiency of decision making units, European Journal of Operational Research, 2, $429-444$.

Charnes A., Cooper W.W. Lewin A.Y. and Seiford L.M. (1994) (eds.), Data envelopment Analysis: Theory, Methodology, and Application. Kluwer Academic Publishers, Boston, MA.

Coli M., Eugenia N. and Agnese R. (2011), Monitoring environmental efficiency: an application to Italian provinces, Environmental Modelling \& Software, 26(1), 38-43.

Cooper W.W., Seiford L.M. and Tone K. (2000), Data Envelopment Analysis, a Comprehensive Test with Models, Applications, References and DEA-Solver Software. Kluwer Academic Publishers, Boston.

Scheel H. (2000), EMS: efficiency measurement system user's manual.Operations Research and Witshaftinsformetik. University of Dortmund, Germany.

Kappos A.D., Bruckmann P., Eikmann T., Englert N., Heinrich U., Höppe P., Koch E., Krause G.H.M., Kreyling W.G., Rauchfuss K., Rombout P., Schulz-Klemp V., Thiel W.R., Wichmann H.-E. (2004), Health effects of particles in ambient air, International Journal of Hygiene and Environmental Health, 207(4), 399-407.

Koelemeijer R.B.A., Homan C.D. and Matthijesen J. (2006), Comparison of special and temporal variations of aerosol optical thickness and particulate matter over Europe, Atmospheric Environment, 40(27), 5304-5315.

Kortelainen M. (2008), Dynamic environmental performance analysis: a Malmquist index approach, Ecological Economics, 64(4), 701-715.

Kuosmanen T. and Kortelainen M. (2005), Measuring eco-efficiency of production with Data Envelopment Analysis, Journal of Industrial Ecology, 9(4), 59-72.

Kuosmanen T. and Kortelainen M. (2007), Valuing environmental factors in cost-benefit analysis using data envelopment analysis, Ecological Economics, 62(1), 56-65.

Kuosmanen T., Bijsterbosch N. and Dellink R. (2009), Environmental cost-benefit analysis of alternative timing strategies in greenhouse gas abatement: A data envelopment analysis approach, Ecological Economics, 68(6), 1633-1642.

Managi S. and Kaneko S. (2009), Environmental performance and returns to pollution abatement in China, Ecological Economics, 68(6), 1643-1651.

Minitab software. www.minitab.com.

Mondal S. and Chakraborty S. (2013), A solution to robot selection problems using data envelopment analysis, International Journal of Industrial Engineering Computations, 4(3), 355-372.

Munksgaard J., Christoffersen L.B., Keiding H., Pedersen O.G. and JensenT.S. (2007), An environmental performance index for products reflecting damage costs, Ecological Economics, 64(1), 119-130.

Nikolić D., Milošević N., Mihajlović I., Živković Ž., Tasić V., Kovačević R. and Petrović N. (2010), Multi-criteria analysis of air pollution with $\mathrm{SO} 2$ and PM10 in urban area around the copper smelter in Bor, Serbia, Water, air, and soil pollution, 206(1-4), 369-383.

Periera M.C., Santos R.C. and Alvim-Ferraz M.C.M. (2007), Air quality improvements using European environment policies: A case study of $\mathrm{SO}_{2}$ in a Coastal Region in Portugal, Journal of Toxicology and Environmental Health, 70(3/4), 347-351.

Picazo-Tadeo A.J., Gómez-Limón J.A. and Reig-Martínez E. (2011), Assessing farming eco-efficiency: A Data Envelopment Analysis approach, Journal of Environmental Management, 92(4), 1154-1164. 
Ramanathan R. (2003), (Ed). An Introduction to data envelopment analysis: a tool for performance measurement. Sage.

Roseland M. (2000), Sustainable community development: integrating environmental, economic, and social objectives, Progress in Planning, 54, 73-132.

Sarkis J. and Cordeiro J.J. (2001), An empirical evaluation of environmental efficiencies and firm performance: pollution prevention versus end-of-pipe practice, European Journal of Operational Research, 135(1), 102-113.

Sarkis J. and Cordeiro J.J. (2012), Ecological modernization in the electrical utility industry: An application of a badsgoods DEA model of ecological and technical efficiency, European Journal of Operational Research, 219(2), 386-395.

Sueyoshi T. and Goto M. (2010), Measurement of a linkage among environmental, operational, and financial performance in Japanese manufacturing firms: A use of Data Envelopment Analysis with strong complementary slackness condition, European Journal of Operational Research, 207(3), 1742-1753.

The Turkish Statistical Institute. www.turkstat.gov.

Yu Y. and Wen Z. (2010), Evaluating China's urban environmental sustainability with Data Envelopment Analysis, Ecological Economics, 69(9), 1748-1755.

Yu Y., Chen D., Zhu B. and Hu S. (2013), Eco-efficiency trends in China, 1978-2010: Decoupling environmental pressure from economic growth, Ecological Indicators, 24, 177-184.

Zhang B., Bi J., Fan Z., Yuan Z. and Ge J. (2008), Eco-efficiency analysis of industrial system in China: a data envelopment analysis approach, Ecological Economics, 68(1), 306-316. 